Copyright (C) 2014 by Academic Publishing House Researcher

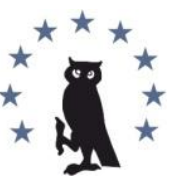

Published in the Russian Federation

European Researcher

Has been issued since 2010.

ISSN 2219-8229

E-ISSN 2224-0136

Vol. 84, No. 10-1, pp. 1806-1812, 2014

DOI: 10.13187/er.2014.84.1806

www.erjournal.ru

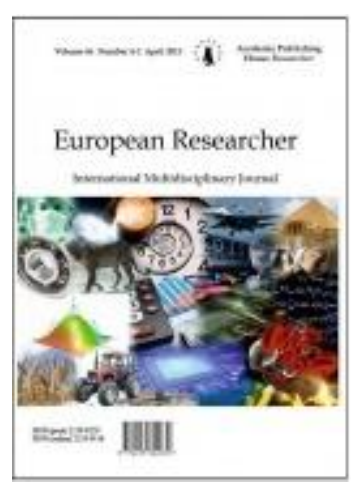

Geosciences

Науки о Земле

UDC 55

\title{
A Comparative Analysis of the Estuary Ecosystems of Russia's Large Rivers in Terms of Anthropogenic Load
}

${ }^{1}$ Olga S. Reshetnyak

${ }^{2}$ Anatoly M. Nikanorov

\begin{abstract}
${ }^{1}$ Institute of Earth Sciences of Southern Federal University, Russian Federation
344090, Rostov-on-Don, Zorge Str., 40

Lecturer of Department of Geoecology and Applied Geochemistry

$\mathrm{PhD}$ (Geography), Senior Researcher

E-mail: olgare1@rambler.ru

${ }^{2}$ Hydrochemical Institute of Hydrometeorology, Russian Federation

344090, Rostov-on-Don, Av. Strikes, 198

Corresponding Member of the RAS, Chief Researcher

Institute of Earth Sciences of Southern Federal

344090, Rostov-on-Don, Zorge Str., 40

Professor, Department of Geoecology and Applied Geochemistry

E-mail: ghi6@aanet.ru
\end{abstract}

\section{Abstract}

Based on monitoring hydro-chemical information, amassed for many years (1980-2012), from the State Service for Observations (SSO), the author conducts an assessment of anthropogenic load on the estuary ecosystems of Russia's large rivers, as well as of their condition by hydro-chemical indicators. The results have helped to rank the estuary ecosystems by anthropogenic load and their condition with a view to identifying the more prosperous ecosystems.

Keywords: estuary ecosystems; hydro-chemical information; anthropogenic load; condition of aquatic ecosystems.

\section{Введение}

Проблема устойчивого экологического и социально-экономического развития отдельных регионов России на современном этапе темно взаимосвязана с решением вопросов охраны и восстановления окружающей среды. Важной составляющей устойчивого этого является сохранение стабильного природного функционирования речных экосистем, что требует изучения региональных особенностей антропогенной трансформации гидролого-экологического состояния речных экосистем в условиях современного антропогенного воздействия. 
Результаты анализа многолетней режимной гидрологической, гидрохимической и гидробиологической информации Федеральной службой по гидрометеорологии и мониторингу окружающей среды показывают, что в современных условиях экстенсивного развития хозяйственной деятельности на водосборах рек происходят нарушения в функционировании речных экосистем за счет ухудшения качества их водной среды и (или) усиления процессов антропогенного экологического регресса [1-6].

Наиболее сильное воздействие на устьевые экосистемы рек оказывают антропогенные изменения речного стока воды, наносов, компонентного состава растворенных веществ. Вследствие замедления скоростей течения и обратных течений в устьях создаются условия для задержки и накопления загрязняющих веществ.

Устьевые области представляют собой «промежуточные» и весьма специфические природные системы, где взаимодействуют, смешиваются и трансформируются два принципиально различных по многим параметрам водных потока (речной и морской) и которые являются своеобразным барьером между рекой и приемным водоемом $[7,8]$.

Учитывая специфику устьевых областей рек, одной из приоритетных задач в области охраны окружающей среды является оценка изменчивости состояния устьевых экосистем и качества их водной среды с учетом региональных особенностей их функционирования и характера антропогенного воздействия, а также оценка уровня антропогенной нагрузки на них.

В настоящее время рассмотрены актуальные вопросы, связанные с оценкой антропогенной нагрузки, которую испытывают устьевые области крупных рек в условиях современного природопользования [8-11]. Однако, несмотря на заметные успехи в этой области, представление об особенностях их функционирования требует дополнительных исследований в части оценки многолетней изменчивости притока растворенных химических веществ на замыкающие створы устьевых областей рек и уровня антропогенной нагрузки на экосистемы.

Специфика антропогенной трансформации компонентного состава водной среды устьевых экосистем крупных рек России и ее направленность определяются региональными особенностями, природными, антропогенными и внутрисистемными факторами формирования химического состава воды, а также уровнем антропогенной нагрузки [1-11].

Особенности природных условий и видов хозяйственной деятельности определяют вклад этих факторов в изменчивости состояния устьевых экосистем. Роль отдельных факторов в трансформации компонентного состава водной среды устьевых экосистем неоднозначна, их совокупное воздействие отражается региональными особенностями их функционирования.

В общей постановке проблема оценки антропогенной нагрузки и состояния устьевых экосистем является в настоящее время одной из ключевых в контексте общей проблемы загрязнения окружающей среды и усиления антропогенного воздействия на поверхностные водные объекты. Решение данной проблемы позволит повысить информативность данных о современном гидролого-экологическом состоянии устьевых областей рек в современных условиях антропогенного воздействия, возможном загрязнении прибрежных акваторий морей и обеспечить разработку экологически обоснованных мероприятий по рациональному использованию и охране их водных ресурсов.

\section{Материалы исследования и методика}

Исследование выполнялось с использованием многолетней информации (за период 1980-2012 гг.) режимно-справочного банка данных Гидрохимического института «Качество поверхностных вод суши». Экологически значимыми считались вариационные ряды, включающие не менее 15-20 лет режимных наблюдений. При выборе объектов исследования исходили из необходимости максимально возможного учета региональных особенностей формирования устьевых экосистем наиболее крупных и значимых рек России. Поэтому рассмотрены данные по состоянию устьевых областей рек Онега, Северная Двина, Печора, Обь, Пур, Таз, Енисей, Лена, Яна, Индигирка, Колыма, Волга, Дон, Кубань, Амур, Раздольная и Камчатка, находящихся в разных регионах и испытывающих разное антропогенное воздействие. 
Методика проведенных исследований включала следующие этапы.

1. Оценка антропогенной нагрузки на устьевые экосистемы проводилась по модулю притока химических веществ на замыкающий створ реки (отражающий суммарный эффект речного переноса и трансформации компонентного состава воды по длине реки) в соответствии с Р 52.24.776-2012. Критерии оценки приведены в таблице 1.

Таблицза 1

\section{Классификатор оценки антропогенной нагрузки по модулю притока растворенных химических веществ [12]}

\begin{tabular}{|l|c|c|c|}
\hline \multirow{2}{*}{$\begin{array}{c}\text { Антропогенная } \\
\text { нагрузка }\end{array}$} & \multicolumn{3}{|c|}{$\begin{array}{c}\text { Диапазон значений модуля притока, превышающих верхнюю } \\
\text { границу модального интервала, т/км² в год }\end{array}$} \\
\cline { 2 - 4 } & $\begin{array}{c}\text { азота } \\
\text { аммонийного }\end{array}$ & $\begin{array}{c}\text { легкоокисляемых } \\
\text { органических веществ }\end{array}$ & нефтепродуктов \\
\hline Малая & до о,о5 & до 0,50 & до 0,05 \\
\hline Умеренная & $0,06-0,10$ & $0,51-1,0$ & $0,06-0,10$ \\
\hline Критическая & $0,11-0,20$ & $1,1-1,5$ & $0,11-0,30$ \\
\hline Высокая & $0,21-0,30$ & $1,6-2,0$ & $0,31-0,50$ \\
\hline Очень высокая & $0,31-0,60$ & $2,1-3,0$ & $0,60-1,00$ \\
\hline Экстремальная & $>0,60$ & $>3,0$ & $>1,00$ \\
\hline
\end{tabular}

2. Оценка изменчивости состояния устьевых экосистем проведена по таким интегральным гидрохимическим показателям, как растворенный в воде кислород, БПК (показатель содержания легкоокисляемых органических веществ - ЛООВ) и азот аммонийный в соответствии с $\mathrm{P}$ 52.24.661-2004. В зависимости от уровня антропогенного воздействия и степени нарушенности состояние водных экосистем условно делится на естественное, равновесное, кризисное, критическое и катастрофическое [13].

Критерии оценки состояния водных экосистем приведены в таблице 2.

3. На основе проведенных оценок сделали ранжирование устьевых экосистем крупных рек России по антропогенной нагрузке и их состоянию для определения наиболее благополучных экосистем.

\section{Классификатор состояния водных экосистем [13]}

\begin{tabular}{|c|c|c|c|}
\hline \multirow[b]{2}{*}{$\begin{array}{l}\text { Состояние } \\
\text { экосистемы }\end{array}$} & \multicolumn{3}{|c|}{$\begin{array}{c}\text { Диапазоны модальных интервалов значений концентраций } \\
\text { (мг/дм³) }\end{array}$} \\
\hline & $\begin{array}{c}\text { минимальных } \\
\text { значений } \\
\text { растворенного в воде } \\
\text { кислорода }\end{array}$ & $\begin{array}{c}\text { легкоокисляемых } \\
\text { органических веществ } \\
\text { по БПК } \\
\end{array}$ & $\begin{array}{l}\text { аммонийного } \\
\text { азота }\end{array}$ \\
\hline Естественное & свыше 6,0 & $0,10-1,0$ & H.O. ${ }^{*}-0,10$ \\
\hline Равновесное & $4,0-6,0$ & $0,50-2,0$ & H.O.-O,5O \\
\hline Кризисное & $2,0-3,9$ & $2,1-4,0$ & $0,51-1,0$ \\
\hline Критическое & $1,0-1,9$ & $4,1-7,0$ & $1,10-3,00$ \\
\hline Катастрофическое & 1,0 & свыше 7,0 & свыше 3,00 \\
\hline
\end{tabular}

\section{Результаты и обсуждение}

Устьевые экосистемы функционируют в условиях постоянной или временной внешней антропогенной нагрузки за счет поступления загрязняющих веществ с речным притоком. В то же время формирование и развитие устьевой области реки в основном определяют гидрологические и геоморфологические факторы, которые включают в себя климатические (метеорологические), речные, морские и общие физико-географические условия, обуславливающие принципиальные различия в состоянии экосистем в разных регионах России [6-8]. Поэтому даже в условиях одинакового антропогенного воздействия отклик 
экосистем будет сугубо индивидуальным, a антропогенная трансформация их экологического состояния в значительной степени будет определяться объемом и составом речных вод.

Результаты ранжирования исследуемых устьевых экосистем по антропогенной нагрузке показали, что большинство экосистем испытывают малую нагрузку по притоку азота аммонийного и нефтепродуктов и умеренную по притоку легкоокисляемых органических веществ (таблица 3).

\section{Ранжирование устьевых экосистем крупных рек по антропогенной нагрузке}

Таблица 3

\begin{tabular}{|c|c|c|c|}
\hline \multirow{2}{*}{$\begin{array}{c}\text { Антропогенная } \\
\text { нагрузка по объемам } \\
\text { притока химических } \\
\text { веществ }\end{array}$} & \multicolumn{3}{|c|}{ Ингредиент } \\
\hline & $\begin{array}{c}\text { Азот } \\
\text { аммонийный }\end{array}$ & $\begin{array}{c}\text { ЛООВ } \\
(\text { по БПК } \\
\text { (п) }\end{array}$ & Нефтепродукты \\
\hline малая & $\begin{array}{l}\text { Лена, Яна, } \\
\text { Индигирка, } \\
\text { Колыма, } \\
\text { Волга, Дон, } \\
\text { Камчатка }\end{array}$ & $\begin{array}{l}\text { Онега, Колыма, } \\
\text { Дон, Кубань }\end{array}$ & $\begin{array}{l}\text { Онега, Северная } \\
\text { Двина, Лена, Яна, } \\
\text { Колыма, Индигирка, } \\
\text { Дон, Амур, } \\
\text { Раздольная }\end{array}$ \\
\hline умеренная & $\begin{array}{l}\text { Онега, } \\
\text { Северная Двина }\end{array}$ & $\begin{array}{l}\text { Северная Двина, Обь, } \\
\text { Енисей, Лена, Яна, } \\
\text { Индигирка, Волга, } \\
\text { Камчатка }\end{array}$ & Волга \\
\hline $\begin{array}{l}\text { от умеренной к } \\
\text { критической }\end{array}$ & $\begin{array}{l}\text { Печора } \\
\text { Кубань }\end{array}$ & Таз & Печора \\
\hline критическая & $\begin{array}{l}\text { Обь, Енисей, } \\
\text { Амур }\end{array}$ & $\begin{array}{l}\text { Печора } \\
\text { Пур }\end{array}$ & $\begin{array}{l}\text { Обь, Таз, Кубань, } \\
\text { Камчатка }\end{array}$ \\
\hline $\begin{array}{l}\text { от критической к } \\
\text { высокой }\end{array}$ & & Амур & Пур, Енисей \\
\hline $\begin{array}{l}\text { высокая и очень } \\
\text { высокая }\end{array}$ & Пур, Таз & Раздольная & \\
\hline $\begin{array}{l}\text { от очень высокой к } \\
\text { экстремальной }\end{array}$ & Раздольная & & \\
\hline
\end{tabular}

Результаты оценки экологического состояния исследуемых устьевых экосистем по таким интегральным гидрохимическим показателям, как БПК ЛООВ) и азот аммонийный, позволили ранжировать экосистемы по их состоянию. По совокупности оценок большинство исследуемых устьевых экосистем по указанным параметрам находятся в «естественном» и (или) «равновесном» состоянии (таблица 4). В то же время по содержанию ЛООВ многие экосистемы находятся в «равновесном» состоянии или переходном в «кризисное».

\section{Ранжирование устьевых экосистем крупных рек по состоянию их абиотической компоненты}

\begin{tabular}{|l|l|l|}
\hline \multicolumn{1}{|c|}{$\begin{array}{c}\text { Состояние устьевых } \\
\text { экосистем }\end{array}$} & \multicolumn{2}{|c|}{\begin{tabular}{c} 
Показатель \\
\cline { 2 - 3 }$($ Ло БПК
\end{tabular}} \\
\hline естественное & Камчатка & $\begin{array}{c}\text { Азот } \\
\text { аммонийный }\end{array}$ \\
\hline $\begin{array}{l}\text { переходное из естественного } \\
\text { в равновесное }\end{array}$ & $\begin{array}{l}\text { Онега, Северная Двина, } \\
\text { Колыма }\end{array}$ & $\begin{array}{l}\text { Печора, Лена, Яна, Колыма, } \\
\text { Волга, Камчатка }\end{array}$ \\
\hline
\end{tabular}




\begin{tabular}{|c|c|c|}
\hline равновесное & $\begin{array}{l}\text { Енисей, Индигирка, } \\
\text { Кубань }\end{array}$ & $\begin{array}{l}\text { Онега, Северная Двина, } \\
\text { Енисей, Индигирка, Дон, } \\
\text { Кубань }\end{array}$ \\
\hline $\begin{array}{l}\text { переходное из естественного } \\
\text { в кризисное }\end{array}$ & Обь, Яна & \\
\hline $\begin{array}{l}\text { переходное из равновесного } \\
\text { в кризисное }\end{array}$ & $\begin{array}{l}\text { Печора, Пур, Волга, } \\
\text { Амур }\end{array}$ & Обь, Таз, Амур \\
\hline кризисное & Таз, Лена & \\
\hline $\begin{array}{l}\text { переходное из равновесного } \\
\text { в критическое }\end{array}$ & Дон & Пур, Раздольная \\
\hline $\begin{array}{l}\text { переходное из равновесного } \\
\text { или кризисного в } \\
\text { катастрофическое }\end{array}$ & Раздольная & \\
\hline
\end{tabular}

Если ранжировать на основе проведенного анализа устьевые экосистемы по антропогенной нагрузке их можно расположить в следующий ряд: pp. Колыма, Дон < pp. Онега, Индигирка, Лена, Яна < рр. Северная Двина, Волга < pp. Камчатка, Кубань < рр. Печора, Обь, Енисей, Амур < рр. Пур, Таз, Раздольная. При ранжировании устьевых экосистем по их экологическому состоянию образуется следующий ряд: рр. Колыма, Камчатка < рр. Онега, Северная Двина, Яна < pp. Печора, Енисей, Индигирка, Волга, Кубань, Лена < рр. Обь, Амур, Дон < рр. Пур, Таз, Раздольная.

Таким образом, можно сказать, что наиболее благополучная обстановка как по антропогенной нагрузке, так и по состоянию характерна для устьевых экосистем рек Онега, Яна, Индигирка и Колыма, а самая напряженная - рек Пур, Таз и Раздольная.

\section{Заключение}

Антропогенное воздействие на водосборах крупных рек России приводит к снижению качества воды и ухудшению их экологического состояния, при этом наибольшую нагрузку испытывают устьевые участки, принимающие речной поток, включающий в себя растворенные и взвешенные вещества, собранные реками с огромных водосборных территорий.

Анализ загрязнения устьевых участков рек некоторыми группами химических веществ и органическими соединениями показал, что антропогенная нагрузка на устьевые экосистемы крупных рек меняется по притоку азота аммонийного от малой (рр. Лена, Яна, Индигирка, Колыма, Волга, Дон, Камчатка) до высокой, очень высокой (рр. Пур, Таз) и даже экстремальной (р. Раздольная); по притоку легкоокисляемых органических веществ от малой (рр. Онега, Колыма, Дон, Кубань) до высокой (рр. Амур, Раздольная); по притоку нефтепродуктов от малой (рp. Онега, Северная Двина, Лена, Яна, Дон и др.) до переходной от критической к высокой (pp. Пур, Енисей).

При такой антропогенной нагрузке на экосистемы устьевых областей за счет речного притока растворенных химических веществ на замыкающие створы исследуемых рек наблюдается трансформация компонентного состава их водной среды и экологического состояния. Оценка состояния устьевых экосистем крупных рек России по гидрохимическим показателям показала, что большинство из них находятся в «естественном» и (или) «равновесном» состояниях.

\section{Благодарности}

Работа выполнена при финансовой поддержке РФФИ (грант № 12-05-00084-а).

\section{Примечания:}

1. Никаноров А.М. Оценка состояния гидробиоценоза на участках водных объектов Кольского Севера с высокой степенью загрязненности воды соединениями меди и никеля / А.М. Никаноров, Л.П. Соколова, Л.С. Косменко, О.С. Решетняк // Метеорология и гидрология, № 11. 2009. С. 69-80. 
2. Никаноров А.М. Антропогенная трансформация компонентного состава водной среды устьевой области р. Лены / А.М. Никаноров, В.А. Брызгало, Л.С. Косменко, О.С. Решетняк // Водные ресурсы, 2011. Том 38. № 2. С. 181-192.

3. Никаноров A.M. Антропогенная трансформация структурной организации гидробиоценоза устьевой области р. Лены / А.М. Никаноров, В.А. Брызгало, Л.С. Косменко, О.С. Решетняк // Водные ресурсы, 2011. Том 38. № 3. С. 306-314.

4. Никаноров А.М. Устьевая область р. Колыма в современных условиях антропогенного воздействия / А.М. Никаноров, В.А. Брызгало, Л.С. Косменко, О.С. Решетняк // Метеорология и гидрология, 2011, № 8. С. 74-88.

5. Решетняк О.С. Антропогенная трансформация водной экосистемы Нижней Волги / О.С. Решетняк, А.М.Никаноров, В.А. Брызгало, Л.С. Косменко // Водные ресурсы, 2013. Tом 40. № 6. С. 623-632.

6. Никаноров А.М. Изменчивость экологического состояния речных зон устьевых экосистем крупных рек России / А.М. Никаноров, В.А. Брызгало, О.С. Решетняк // Вода: химия и экология, № 12, 2013. С.15-21.

7. Эстуарно-дельтовые системы России и Китая: гидролого-морфологические процессы, геоморфология и прогноз развития. М.: ГЕОС. 2007. 445 с.

8. Никаноров А.М., Брызгало В.А. Реки России. Часть II. Реки Европейского Севера и Сибири. Ростов-на-Дону: Изд-во «НОК», 2010. 296 с.

9. Никаноров А.М., Иванов В.В., Брызгало В.А. Реки Российской Арктики в современных условиях антропогенного воздействия. Ростов-на-Дону: Изд-во «НОК». 2007. 280 c.

10. Никаноров А.М. Роль речного притока растворенных химических веществ в антропогенной трансформации состояния водной среды устьевой области р. Волга / А.М. Никаноров, В.А. Брызгало, Л.С. Косменко, М.Ю. Кондакова, О.С. Решетняк // Вода: химия и экология, № 7, 2010, С. 6-12.

11. Никаноров А.М. Антропогенная нагрузка на устьевую область р.Дон в современных условиях техногенного воздействии / А.М. Никаноров, В.А. Брызгало, Л.С. Косменко, М.Ю. Кондакова, О.С. Решетняк // Вода: химия и экология, № 1, 2011, С. 4-10.

12. $\mathrm{P}$ 52.24.776-2012. Рекомендации. Оценка антропогенной нагрузки и риска воздействия на устьевые области рек с учетом их региональных особенностей. Ростов н/Д: Росгидромет, ФГБУ «ГХИ», 2012. 28 с.

13. Р 52.24.661-2004. Рекомендации. Оценка риска антропогенного воздействия приоритетных загрязняющих веществ на поверхностные воды суши. М.: Метеоагенство Росгидромета. 2006. 26 с.

\section{References:}

1. Nikanorov A.M. Otsenka sostoyaniya gidrobiotsenoza na uchastkakh vodnykh ob"ektov Kol'skogo Severa s vysokoi stepen'yu zagryaznennosti vody soedineniyami medi i nikelya / A.M. Nikanorov, L.P. Sokolova, L.S. Kosmenko, O.S. Reshetnyak // Meteorologiya i gidrologiya, № 11. 2009. S. 69-80.

2. Nikanorov A.M. Antropogennaya transformatsiya komponentnogo sostava vodnoi sredy ust'evoi oblasti r. Leny / A.M. Nikanorov, V.A. Bryzgalo, L.S. Kosmenko, O.S. Reshetnyak // Vodnye resursy, 2011. Tom 38. № 2. S. 181-192.

3. Nikanorov A.M. Antropogennaya transformatsiya strukturnoi organizatsii gidrobiotsenoza ust'evoi oblasti r. Leny / A.M. Nikanorov, V.A. Bryzgalo, L.S. Kosmenko, O.S. Reshetnyak // Vodnye resursy, 2011. Tom 38. № 3. S. 306-314.

4. Nikanorov A.M. Ust'evaya oblast' r. Kolyma v sovremennykh usloviyakh antropogennogo vozdeistviya / A.M. Nikanorov, V.A. Bryzgalo, L.S. Kosmenko, O.S. Reshetnyak // Meteorologiya i gidrologiya, 2011, № 8. S. 74-88.

5. Reshetnyak O.S. Antropogennaya transformatsiya vodnoi ekosistemy Nizhnei Volgi / O.S. Reshetnyak, A.M.Nikanorov, V.A. Bryzgalo, L.S. Kosmenko // Vodnye resursy, 2013. Tom 40. № 6. S. 623-632.

6. Nikanorov A.M. Izmenchivost' ekologicheskogo sostoyaniya rechnykh zon ust'evykh ekosistem krupnykh rek Rossii / A.M. Nikanorov, V.A. Bryzgalo, O.S. Reshetnyak // Voda: khimiya i ekologiya, № 12, 2013. S. 15-21. 
7. Estuarno-del'tovye sistemy Rossii i Kitaya: gidrologo-morfologicheskie protsessy, geomorfologiya i prognoz razvitiya. M.: GEOS. 2007. $445 \mathrm{~s}$.

8. Nikanorov A.M., Bryzgalo V.A. Reki Rossii. Chast' II. Reki Evropeiskogo Severa i Sibiri. Rostov-na-Donu: Izd-vo «NOK», 2010. 296 s.

9. Nikanorov A.M., Ivanov V.V., Bryzgalo V.A. Reki Rossiiskoi Arktiki v sovremennykh usloviyakh antropogennogo vozdeistviya. Rostov-na-Donu: Izd-vo «NOK». 2007. 280 s.

10. Nikanorov A.M. Rol' rechnogo pritoka rastvorennykh khimicheskikh veshchestv $\mathrm{v}$ antropogennoi transformatsii sostoyaniya vodnoi sredy ust'evoi oblasti r. Volga / A.M. Nikanorov, V.A. Bryzgalo, L.S. Kosmenko, M.Yu. Kondakova, O.S. Reshetnyak // Voda: khimiya i ekologiya, № 7, 2010, S. 6-12.

11. Nikanorov A.M. Antropogennaya nagruzka na ust'evuyu oblast' r.Don v sovremennykh usloviyakh tekhnogennogo vozdeistvii / A.M. Nikanorov, V.A. Bryzgalo, L.S. Kosmenko, M.Yu. Kondakova, O.S. Reshetnyak // Voda: khimiya i ekologiya, № 1, 2011, S. 4-10.

12. $\mathrm{R}$ 52.24.776-2012. Rekomendatsii. Otsenka antropogennoi nagruzki i riska vozdeistviya na ust'evye oblasti rek s uchetom ikh regional'nykh osobennostei. Rostov n/D: Rosgidromet, FGBU «GKhI», 2012. $28 \mathrm{~s}$.

13. R 52.24.661-2004. Rekomendatsii. Otsenka riska antropogennogo vozdeistviya prioritetnykh zagryaznyayushchikh veshchestv na poverkhnostnye vody sushi. M.: Meteoagenstvo Rosgidrometa. 2006. $26 \mathrm{~s}$.

УДК 504.064

\title{
Сравнительный анализ устьевых экосистем крупных рек России по антропогенной нагрузке
}

\author{
${ }^{1}$ Ольга Сергеевна Решетняк \\ ${ }^{2}$ Анатолий Максимович Никаноров
}

${ }^{1}$ Институт наук о Земле Южного Федерального университета, Российская Федерация 344090, г.Ростов-на-Дону, ул. Зорге, 40

Преподаватель кафедры геоэкологии и прикладной геохимии

к.г.н., стар. науч. сотр.

E-mail: olgare1@rambler.ru

2 ФГБУ «Гидрохимический институт» Росгидромета, Российская Федерация

344090, г.Ростов-на-Дону, проспект Стачки, 198

Чл.-корр. РАН, глав. науч. сотр.

Институт наук о Земле Южного Федерального университета, Российская Федерация 344090, г.Ростов-на-Дону, ул.Зорге, 40

Профессор кафедры геоэкологии и прикладной геохимии

E-mail: ghi6@aanet.ru

Аннотация. На основе многолетней (1980-2012 гг.) режимной гидрохимической информации Государственной службы наблюдений $(\Gamma \mathrm{CH})$ проведена оценка антропогенной нагрузки на устьевые экосистемы крупных рек России, а также их состояния по гидрохимическим показателям. Результаты позволили ранжировать устьевые экосистемы по антропогенной нагрузке и их состоянию для определения наиболее благополучных экосистем.

Ключевые слова: устьевые экосистемы; гидрохимическая информация; антропогенная нагрузка; состояние водных экосистем. 